\title{
Defect detection strategies in Nickel Superalloys welds using active thermography
}

\author{
by A. García de la Yedra*, E. Fernández*, A. Beizama*, R. Fuente*, A. Echeverria*, P. Broberg*^ A. \\ Runnemalm ** and P. Henrikson*** \\ * Control and Evaluation, IK4-LORTEK; Arranomendia Kalea 4A, Ordizia, Spain; agarciadelayedra@lortek.es \\ **Dept. of Engineering Science, University West; SE-46186, Trollhättan, Sweden; anna.runnemalm@hv.se \\ *** Dept. of Research \& Technology, GKN Aerospace Engine Systems, SE-46181, Trollhättan,; Sweden
}

\begin{abstract}
As a result of extreme operation conditions in gas turbines, high resistance materials with excellent behaviour at high temperature are required. Alloys, such as MarM-247 nickel based superalloy, with excellent mechanical properties at very high temperature (even at $85 \%$ of their melting point) are being used in these applications. This extraordinary behaviour is mainly due to the presence of a strengthening phase ( $\left.\mathrm{Y}^{\prime}\right)$ with the following chemical composition: $\mathrm{Ni}_{3}\left(\mathrm{Al}, \mathrm{Ti}^{\mathrm{i}}\right.$. However, during welding these materials are susceptible to cracking and this is why weld inspections become crucial. In this work different strategies for defect detection in welds are introduced, all of them based on active thermography. The work covers aspects such as different excitation and data evaluation strategies.
\end{abstract}

\section{Introduction}

The continuous search for more efficient gas turbines has evolved into a considerable temperature increase within the thermo-dynamical cycle of aero-engines and land based turbines. This has also caused extreme requirements for those components that are placed along the hot gas path. That is the case of vanes, blades or discs that are subjected to cyclic loadings under severe corrosive and high temperature conditions. Nickel based superalloys meet properly these requirements since they combine high mechanical strength with good resistance to creep and corrosion. This is due to their highly alloyed nature and complex precipitation strengthening mechanisms. However, this complex metallurgical behaviour presents some problems during the manufacturing process and more precisely during welding. The $y^{\prime}$ strengthened alloys are susceptible to cracking under the thermal and mechanical loadings generated by the heat source due to local modifications in the microstructure and subsequent mechanical properties changes. Typically, cracks may be classified into three types according to their generation source: a) solidification cracking at the weld bead due to shrinkage strains, b) grain boundary liquation cracking within adjacent heat affected zone (HAZ) and c) strain age cracking due to residual stresses developed during manufacturing [1].

The presence of a crack in a component under fatigue loadings and high temperature conditions has to be avoided since it could grow rapidly with fatal consequences. Due to this fact, the inspection of welded Ni superalloy parts is crucial, both in manufacturing and in-service maintenance. Currently, inspections are performed through traditional NDT such as Liquid Penetrant (LPT) or Visual Testing (VT) techniques, being both of them very time consuming, manual and operator skills dependent. Active infrared thermography (IRT) presents a good alternative for large areas inspection (covering a wide field of view) in a fast manner, obtaining operator independent results with the possibility of recording the whole inspection.

Active IR thermography is widely used for defects detection (surface and sub-surface in some materials) in different materials such as plastics, composites or metals. The usual experimental configuration relies on the use of an Infrared camera for recording thermal transient response after a thermal excitation via halogen or flash lamps (modulated or pulsed). More and more, different excitation sources are being introduced for surface cracks detection, among them; local heating via laser [2, 3] as well as induction heating through coils [4] or heat gun.

Another interesting field is data analysis for defects detection and sizing. Generally, raw images are not suitable for defect detection and require some processing techniques that allow distinguishing non-defective areas (also known as sane area) from defective ones. Some of them are based on widely known processing techniques as Thermal Contrast Techniques (TCT), Thermal Signal Reconstruction (TSR) or Fast Fourier Transformation (FFT) [5] while some other authors suggest new processing techniques based on statistical approaches or laser footprint analysis [6]. In this work laser, induction and heat gun excitation sources are compared for their applicability in welds inspection including different data analysis methods. 


\section{Experimental Procedure}

The experimental procedure consisted of two main steps: manufacturing of reference samples and preparation of experimental set-up.

\section{1- Samples}

The manufactured samples were made of Inconel 718 and MarM-247 Nickel based superalloys with the following chemical composition and thermal properties:

Table 1. Inconel 718 and MarM-247 chemical composition (wt.\%)

\begin{tabular}{|c|c|c|c|}
\multicolumn{2}{c}{ INCONEL 718 } & \multicolumn{2}{c|}{ MARM- 247 } \\
Element & Content & Element & Content \\
\hline $\mathrm{Ni} \& \mathrm{Co}$ & $50-55 \%$ & $\mathrm{Ni}$ & Bal. \\
\hline $\mathrm{Cr}$ & $17-21 \%$ & $\mathrm{Cr}$ & $8-8.5 \%$ \\
\hline $\mathrm{Fe}$ & $\mathrm{Bal}$ & $\mathrm{Co}$ & $9-9.5 \%$ \\
\hline $\mathrm{Nb} \mathrm{\&} \mathrm{Ta}$ & $4.75-5.5 \%$ & $\mathrm{~W}$ & $9.3-9.7 \%$ \\
\hline $\mathrm{Mo}$ & $2.8-3.3 \%$ & $\mathrm{Mo}$ & $0.7-0.78 \%$ \\
\hline $\mathrm{Ti}$ & $0.65-1.15 \%$ & $\mathrm{Ti}$ & $5.4-5.6 \%$ \\
\hline $\mathrm{Al}$ & $0.2-0.8 \%$ & $\mathrm{Al}$ & $1-1.1 \%$ \\
\hline
\end{tabular}

Table 2. Inconel 718 and MarM-247 thermal properties

\begin{tabular}{|c|c|c|}
\hline Property & INCONEL 718 & MARM- 247 \\
\hline Density & $8.19 \mathrm{~g} / \mathrm{cm}^{3}$ & $8.5 \mathrm{~g} / \mathrm{cm}^{3}$ \\
\hline Specific heat & $435 \mathrm{~J} / \mathrm{kg} .{ }^{\circ} \mathrm{C}$ & $460 \mathrm{~J} / \mathrm{kg} .{ }^{\circ} \mathrm{C}$ \\
\hline Thermal Conductivity & $10.6 \mathrm{~W} / \mathrm{m} .{ }^{\circ} \mathrm{C}$ & $12 \mathrm{~W} / \mathrm{m} .{ }^{\circ} \mathrm{C}$ \\
\hline Thermal Diffusivity & $2.97 .10^{-6} \mathrm{~m}^{2} / \mathrm{s}$ & $3.06 .10^{-6} \mathrm{~m}^{2} / \mathrm{s}$ \\
\hline
\end{tabular}

It has to be noted that the main difference between both materials - apart from the obvious higher iron content in Inconel 718 - is the higher Al and Ti content in MarM-247. These two elements together with Ni made up the main strengthening phase of Ni based superalloys; gamma prime phase ( $\left.\mathrm{Y}^{\prime}\right)$ with $\mathrm{Ni}_{3}(\mathrm{Al}, \mathrm{Ti})$ composition. The presence of this hardening phase provides these alloys with excellent mechanical properties even at very high temperatures. However, during welding its presence turns superalloys into difficult to weld materials and consequently susceptible to cracking. This is exclusively critical for the case of MarM-247 alloy which is hardened by y' precipitates while in Inconel 718 (developed for lower temperature applications such as discs) this phase appears in a lower percentage, leading to a much better weldability. In spite of this fact, in this work both materials were inspected because of the critical nature of cracks in components withstanding high temperatures and loads.

Plates were welded via two different welding techniques: Laser Beam Welding (LBW) and Tungsten Inert Gas (TIG). The samples shape was of rectangular section, between $50 \mathrm{~mm}$ and $150 \mathrm{~mm}$ length and $4 \mathrm{~mm}$ thick. During the manufacturing process, welding parameters were chosen in such a manner that natural defects were generated. An example is depicted in Figure 1, where a MarM-247 welded plate shows clear transverse cracks along the weld bead including some pores.

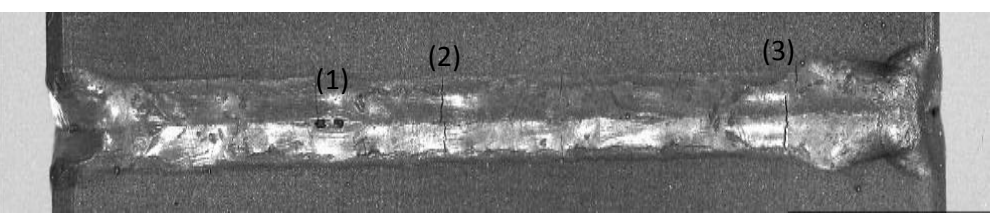

Figure 1. MarM-247 welded plate with transverse cracks and pores - sample 1-

In those cases where crack generation during welding did not occur -mainly in Inconel 718 samples due to the mentioned lower Al and Ti content - artificial notches were machined via Electrical Discharge Machining (EDM). Details about tested samples and the corresponding crack and notches dimensions are collected in the following table: 
Table 3. Employed samples

\begin{tabular}{|c|c|c|c|c|}
\hline Sampe $\mathrm{N}^{\mathrm{o}}$ & Material & $\begin{array}{l}\text { Welding } \\
\text { Technique }\end{array}$ & Defects & Images \\
\hline 1 & MarM-247 & LBW & $\begin{array}{l}\text { Transverse Cracks: as } \\
\text { small as } 50 \mu \mathrm{m} \text { and } \\
\text { pores around } 0.5 \mathrm{~mm} \\
\text { in diameter }\end{array}$ & \\
\hline 2 & Inconel 718 & $\begin{array}{c}\text { TIG } \\
\text { (grinded) }\end{array}$ & $\begin{array}{c}\text { Two notches: } \mathrm{L}=1 \\
\text { mm and } 2 \mathrm{~mm} \text {, } \\
\mathrm{W}=0.1 \mathrm{~mm} \text { and } \\
\mathrm{D}=0.5 \mathrm{~mm}\end{array}$ & \\
\hline 3 & Inconel 718 & TIG & $\begin{array}{c}\text { Two equal notches at } \\
\text { weld edge: } \mathrm{L}=1 \mathrm{~mm} \text {, } \\
\mathrm{W}=0.1 \mathrm{~mm} \text { and } \\
\mathrm{D}=0.5 \mathrm{~mm}\end{array}$ & \\
\hline 4 & MarM-247 & LBW & $\begin{array}{l}\text { Transverse cracks } \\
\text { with a width down to } \\
50 \mu \mathrm{m} .\end{array}$ & \\
\hline
\end{tabular}

\section{2- Experimental set-ups}

Three different experimental configurations were used in this work, each of them related to one excitation system: laser, induction and heat gun. Details about these set-ups are found in the following paragraphs.

\section{a) Laser}

Laser excitation presents a good alternative for its use as a heat source in Active Thermography. The local heating supplied allows identifying changes in thermal conductivity which are typically ascribed to cracks presence. In addition, object scanning is possible, allowing inspection of large areas or long welds, as in this case.

When a laser beam is projected onto a metallic surface, considerable amount of light will be reflected. The lower the emissivity of that surface the higher will be the reflected amount of light. On the other hand, under the presence of a surface breaking crack, the defect will behave as a cavity where multiple reflections occur resulting in higher light absorption and subsequent temperature increment. In this manner, by means of an IR camera, this over-heating may be detected in order to distinguish non-defective areas from defective ones.

In this work, a semiconductor laser was employed which provided an output power of $10 \mathrm{~W}$ at $1064 \mathrm{~nm}$ wavelength having a spot diameter around $1 \mathrm{~mm}$. The thermal sequence was recorded via a microbolometer based IRcamera, sensitive in the 7.5-14 $\mu \mathrm{m}$ wavelength range and covering a field of view of $120 \mathrm{~mm} \times 90 \mathrm{~mm}$ by standard lens $\left(25^{\circ}\right)$. A scheme illustrating the explained configuration is shown in Figure 2: 


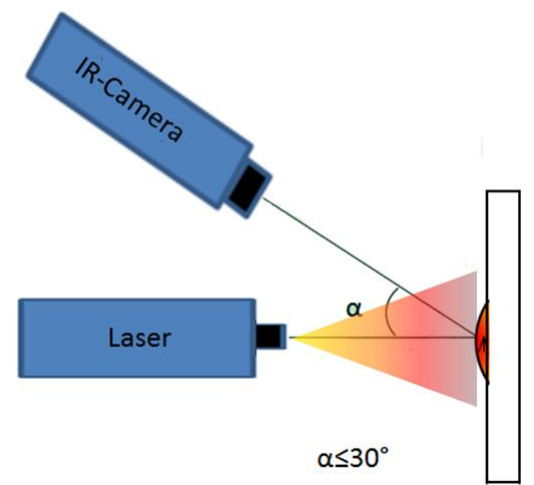

Figure 2. Weld inspection scheme for laser excited Active Thermography

An optical lens assembly was designed in order to turn the spot into a high density laser line with sufficient length to cover the weld width including the heat affected zone. In addition, the laser line width was reduced from its initial size thanks to the use of cylindrical lens. In this manner, high power density line was projected onto the surface with which optimum results were obtained. The power density was around $50 \mathrm{~W} / \mathrm{cm}^{2}$. With this configuration samples were scanned at different speed: from $100 \mathrm{~mm} / \mathrm{min}$ to $500 \mathrm{~mm} / \mathrm{min}$. An example is illustrated in Figure 3 where the setup may be observed together with a clear indication of a $0.1 \mathrm{~mm} \times 1 \mathrm{~mm}$ notch in sample 2 .

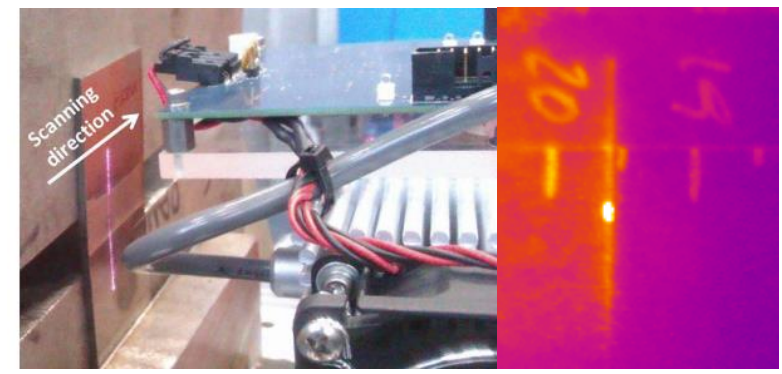

Figure 3. Experimental set-up for laser Active Thermography and clear indication of a notch in a flat plate with a marked rule

Similarly, thermal profile of the sample 1 (shown in Figure 1) is illustrated in Figure 4 after the scanning process. Peak temperatures are revealed as clear indications of cracks presence.

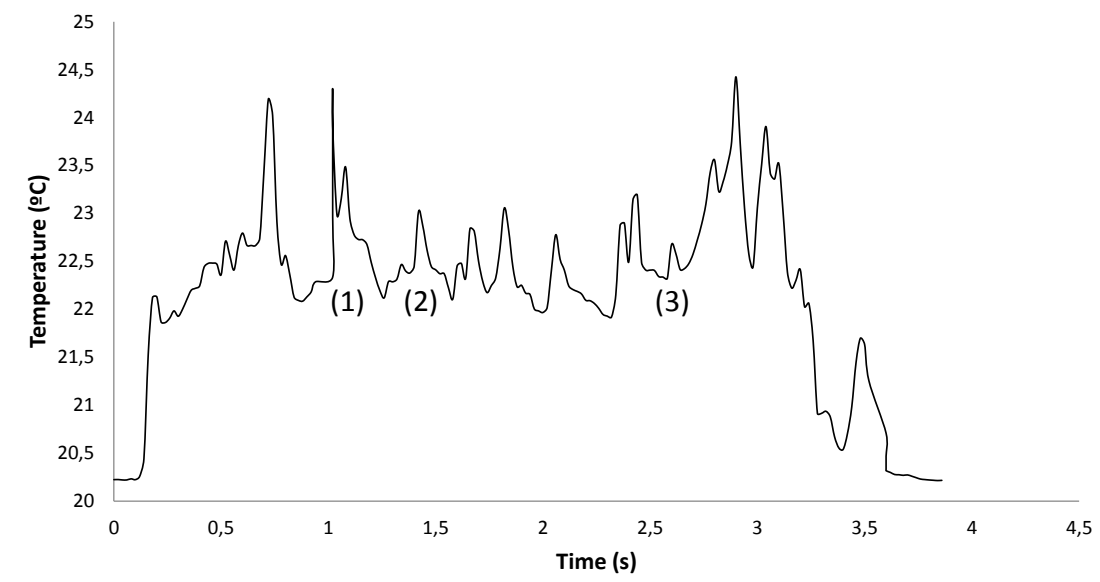

Figure 4. Sample 1 centreline thermal profile after scanning 


\section{b) Induction}

During the test with induction heating, a water cooled induction coil was placed in front of the weld (see Figure 5). The distance between the coil and the test sample was $2 \mathrm{~mm}$. The infrared thermography system used for the experiments was a FLIR SC 5650 infrared camera with a band width of $2.5-5.1 \mu \mathrm{m}$ and a $27 \mathrm{~mm}$ optical lens. The camera had an InSb detector with a resolution of 640x512 pixels and the frame rate during the recording was 50 fps (frames per second). The test sample used for the induction heating test was sample No 4.

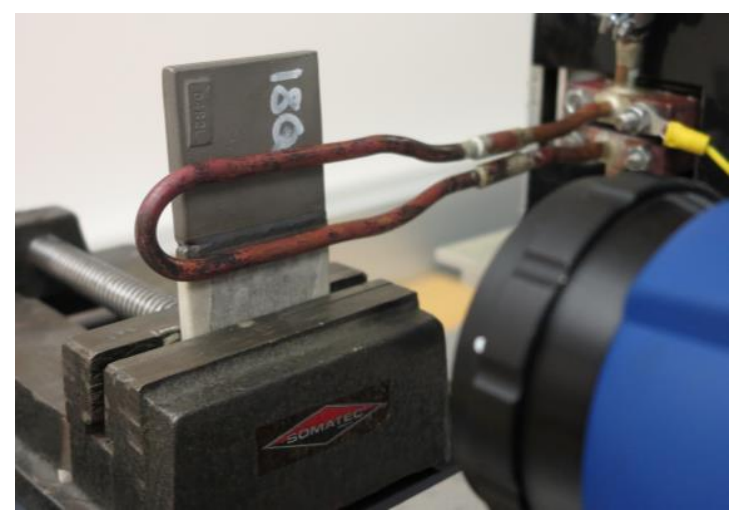

Figure 5. Test set up for induction heating

\section{c) Heat Gun}

During heat gun experiments, the object was heated in a step-heating mode and the surface temperature increment was monitored via IR camera. The employed heat gun had a maximum power of $1500 \mathrm{~W}$ and the sample was heated via two different configurations: transmission and reflection mode. The typical behaviour under these conditions may be observed in Figure 6 . As illustrated in the figure non-defective areas and defective ones behaved in a different manner, being the slope of the former much less steeper due to the higher absorption in defective zones. It is also important to emphasize that those areas with different surface conditions, i.e. different emissivity, were revealed as peak temperatures (marked rule, for instance). An important step within data analysis section was to discard those "fake defects" through thermogram and image processing techniques.
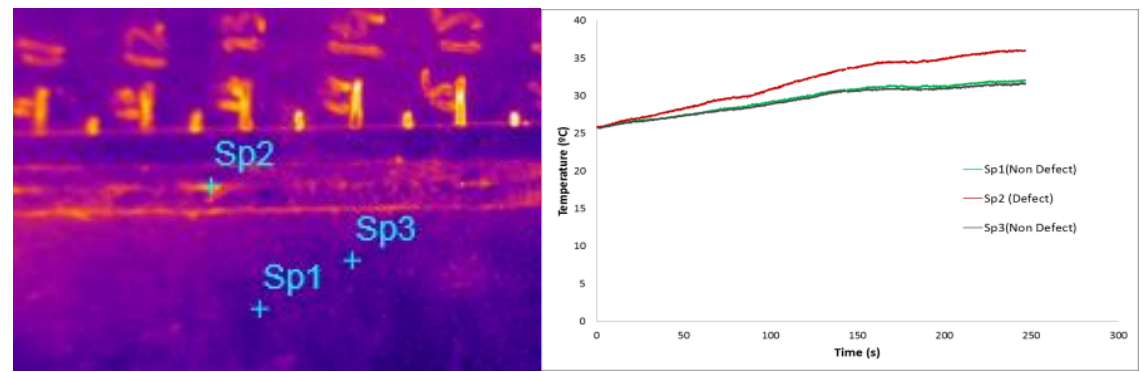

Figure 6. Weld thermogram during heat gun experiment and non-defective/defect zones behaviour differences

\section{3- Data Analysis}

\section{1- Review of common techniques}

During the last years, several methods for thermographic sequences processing have been evolved. Many of these techniques may be found in the traditional artificial vision field in which software mimics the human eye by interpreting the acquired images. Within these processing techniques, smoothing operations for noise removal (median, Gaussian filters...), gradient operations for edge detection (Sobel, Canny...) or morphological filtering for objects recognition (thresholding, objects parameter identification, Hough transform...) may be found. Even though these techniques are really useful for enhancing IR images, generally they are not sufficient for defect detection due to heterogeneous heating effects, surface condition variations etc...that disturb the thermograms automated interpretation. 
Another common approach deals with distinguishing defects from sane areas by thermal properties such as conductivity or diffusivity. These techniques are less sensitive to surface conditions and consequently provide clearer information of the defects. In Pulsed Thermography, for instance, the temperature decay after a short pulse is recorded and the evolution of each pixel is transformed into frequency domain through one dimensional Discrete Fourier Transform (DFT). Phase variations are generally less susceptible to heterogeneities giving more clear evidences of different diffusivity areas, that is, defects. It is also a common practice to conduct smoothing operations for noise avoidance especially prior to DFT application. Thermal Signal Reconstruction is a clear example. In this technique the cooling process is analyzed and modelled based on the assumption that a non-defected zone should follow the expression given by the 1D heat transfer general solution. In a logarithmic scale this is a first order logarithmic polynomial which is fitted for two main purposes: noise removal and cooling rate assessment. It is widely accepted that defective cracks cooling capacity is much lower due to the air they contain which acts as an insulator. Finally, thermal contrast techniques are the easiest ones. Although its application is straightforward, they are generally complex to be automated. This occurs due to the inconvenience of defining a reference area (flawless), especially if the specimen is unknown. In this field, differential absolute contrast (DAC) technique allows defining the sane area through the cooling modelling.

\section{2-Data analysis procedure}

In the field of laser line heating, the data analysis procedure consisted of different steps that include: a) laser line automated detection, b) image reconstruction after scanning, c) relative temperature increment assessment and d) temperature gradient calculation.

Image resolution was 640 pixels $\times 480$ pixels, giving a sequence length longer than 3000 frames for a frame rate equal to $25 \mathrm{fps}$ (frames per second). After the thermogram sequence acquisition, first step was devoted to select the information of interest, that is, the one under the laser line and its surroundings. That was done thanks to image segmentation tools which formed the first step for turning the 3D matrix into a 2D image containing the heated weld (see Figure 7). In order to properly represent the bead weld, the scanning speed and the instantaneous field of view were considered for image reconstruction. In this manner, distorted images due to improper reconstruction were avoided.

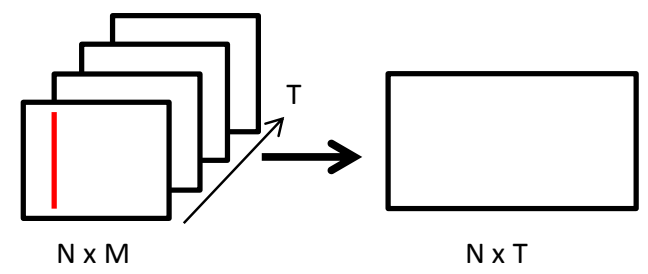

Figure 7. Thermogram reconstruction process

A key aspect when inspecting welds is the high noise level which often disturbs the cracks detection. This is due to the surface irregularities or different emissivity values in the weld bead with respect to the heat affected zone that leads to heterogeneous heating. An interesting approach for overcoming the problems arising in noisy environments is to assess relative temperature increments instead of absolute values. In this work, the pre-heating condition of the samples (in order to assess emissivity variations or surface roughness effects) and the laser line temperature increment were considered. For that purpose, the unheated sample was scanned and the laser heat supply was added to this recording (the increment was assessed as the temperature rise over a non-defected area).

Final operation consisted of subtracting this theoretical temperature increment from the acquired thermal sequence, enhancing in this manner those areas that exceeded the assessed profile. An example of the abovementioned procedure is illustrated in Figure 8 where absolute temperature increment (blue line) and theoretical increment as a result of summing the pre-heating state and the temperature rise (green line) are plotted. It is observed that most of the peaks match in such a way that the subtracting operation removes considerably the noise level. In this manner, the influence of emissivity variations is reduced and simply defect effects are revealed. 


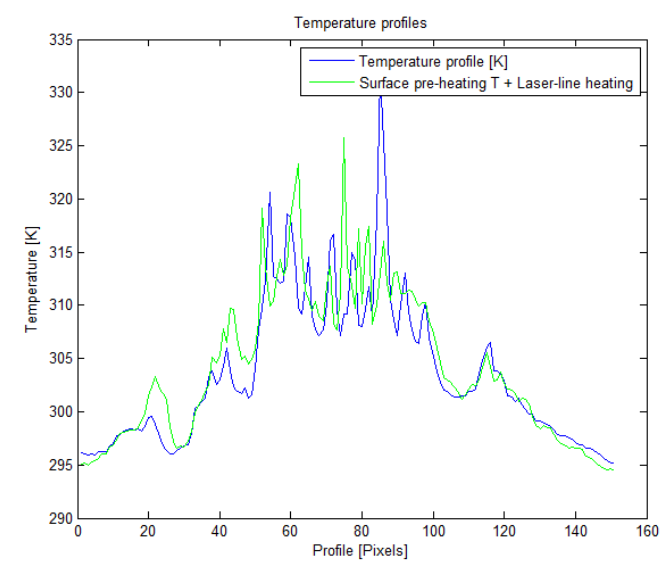

Figure 8. Acquired temperature profile vs. surface pre-heating state plus laser-line temperature rise

A similar procedure was followed in the case of gun heating, although some steps such as relative temperature increments or segmentation and scanning cannot be performed in a straightforward manner as in laser-line heating.

The data analysis of the images from the induction heating test was performed by fitting a polynomial function of the heating phase in each pixel. By calculating the derivative in each pixel, the rate of heating over the test sample could be compared. In a defect free surface, the heating will be even, but in the presence of a crack a characteristic heating pattern will appear. Due to the current flow around the crack, the tips will heat up faster than the opening in the middle of the crack.

\section{Results}

Results for gun heating are illustrated in the following figures (Figure 9 and Figure 10). Tests were performed over both: flat surfaces (grinded weld) and welds without any machining operations (sample 3). In flat surfaces, as is the case of sample 2, notches are clearly revealed. In Figure 9 , the magnitude of the thermal gradient is illustrated with clear indications of two notches with $0.1 \mathrm{~mm}$ width, $0.5 \mathrm{~mm}$ depth and $1 \mathrm{~mm}$ and $2 \mathrm{~mm}$ length. The high signal to noise relation is perceived at first glance.

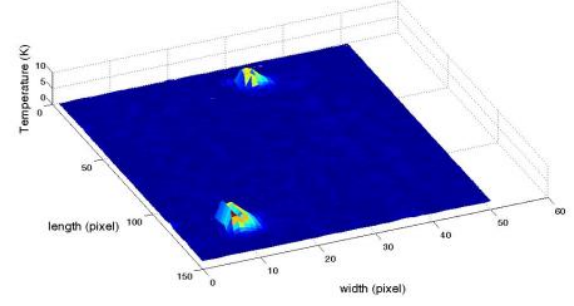

Figure 9. Sample 2 thermal gradient after heat gun experiment

Under noisy environments, the obtained results also revealed notches even though in this latter case the required heating for surpassing the underlying noise was considerably higher than in flat surfaces. While in the former case an increment of $10^{\circ} \mathrm{C}$ was sufficient, in the latter increments around $50{ }^{\circ} \mathrm{C}$ were required for obtaining similar signal to noise ratio in a $0.1 \mathrm{~mm}$ width notch (see Figure 10). 


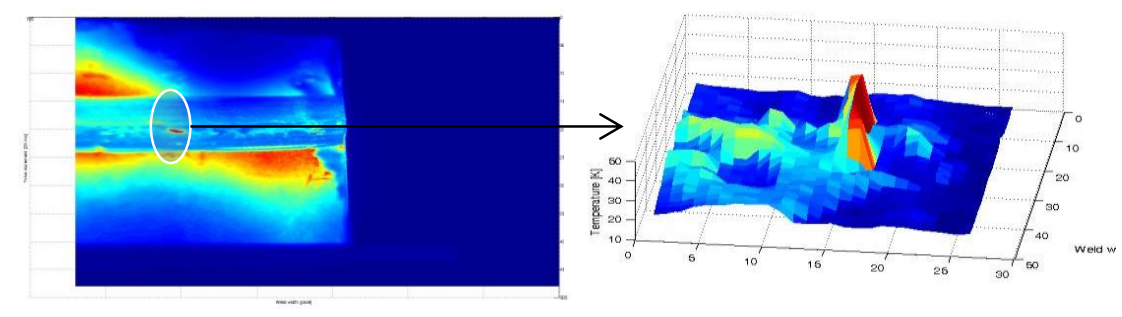

Figure 10. Sample 3 thermal profile after heat gun experiment

On the other hand, laser line strategy provided good results even for cracks as small as $50 \mu \mathrm{m}$ width and around $2 \mathrm{~mm}$ in length. In Figure 11, results obtained by this procedure are illustrated and compared with a visual inspection thanks to the images obtained via microscopy. As observed, microscopy images and processed thermal profiles are in good agreement showing both of them pores and transversal cracks. The magnitude of the gradient is also included, revealing defect edges.
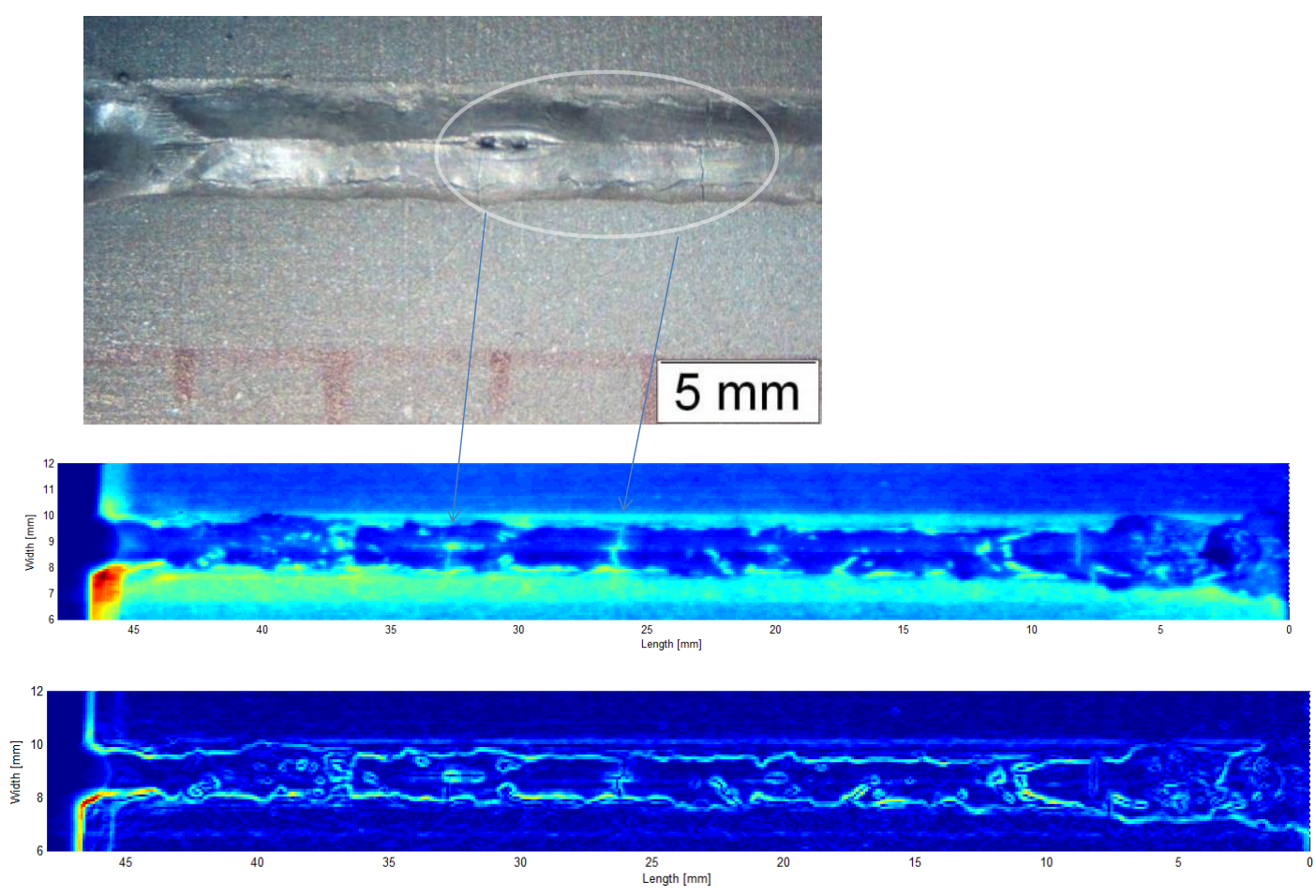

Figure 11. Sample 1 results with laser-line scanning strategy: tested sample showing transversal cracks and pores, reconstructed temperature profile and thermal gradient magnitude revealing defect edges

Result from a test with induction heating as excitation on test sample No 4 is shown in Figure 12 . The time derivative of the cooling phase is presented. Four surface cracks are clearly visible at $6,14,26$ and $35 \mathrm{~mm}$ along the weld in the figure. Two minor cracks can also be seen at 8 and $20 \mathrm{~mm}$. The cracks have a typical dimension of $2 \mathrm{~mm}$ in length and 0.05 in width.

The crack tips are visible as areas with high heating rate. Across the opening of the cracks the heating is slower for a wider than for a narrow crack, comparing the crack at $35 \mathrm{~mm}$ (wider crack) and at $26 \mathrm{~mm}$ (narrower crack). This can be used for estimating the size of the defects. 


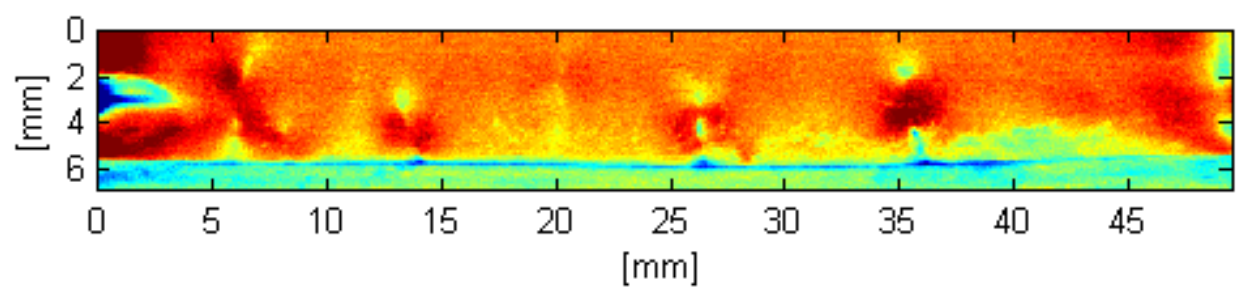

Figure 12. Time derivative of the cooling phase using inductive heating as excitation

\section{5- Conclusions}

After completing this work, the following conclusions may be drawn:

a) In this work, the feasibility of using IRT for defects detection in welded parts was shown. This result highlights that IRT is a promising technique for replacing traditional NDT (visual inspection, liquid penetrant...), avoiding, in this manner, manual procedures and human factor (user/operator subjective decisions).

b) The importance of thermal images processing was proved in this work. It was observed that even though raw images contained peak temperatures corresponding with defects, they also included peaks as a result of surface irregularities or areas with different emissivity. Two approaches were used in this work for overcoming this problem: relative temperature increments and cooling rate assessment. By means of these procedures, background noise was reduced considerably and defects were revealed clearly.

c) Regarding excitation sources, three different methods were employed: laser, gun heating and induction. Good results were obtained with the chosen techniques, although laser line heating provided better signal to noise ratio than heat gun in welds. This is due to the more effective absorption in the case of light with respect to air. Similarly, by means of an induction coil the overheating at the crack tips due to electric current concentration was clearly observed and found useful for defect detection.

\section{Acknowledgment}

The research leading to these results has received funding from the European Community's Seventh framework Programme FP7 2007-2013 under grant agreement number 323427: WELDMINDT project. The work was carried out in cooperation with GKN Aerospace Engine Systems. Authors are grateful for the received financial support and samples.

\section{REFERENCES}

[1] S. Kou, "Precipitation hardening materials. Chapter II - Nickel base alloys". Welding Metallurgy. John Wiley \& Sons, pp. 297-316, 1987.

[2] P. Broberg, "Surface crack detection in welds using thermography", NDT \& E International vol. 57 pp. 69-73, 2013.

[3] D. P. Almond et al., "Thermographic techniques for the detection of cracks in metallic components", Insight vol. 53(11), pp. 614-620, 2011.

[4] B. Weekes, D. P. Almond, P. Cawley, and T. Barden, "Eddy-current induced thermography-probability of detection study of small fatigue cracks in steel, titanium and nickel-based superalloy", NDT \& E International, vol. 49, pp. 47-56, 2012.

[5] C. Ibarra-Castanedo et al. "Infrared image processing and data analysis", Infrared Physics \& Technology, vol. 46(1), pp. 75-83, 2004.

[6] J. Schlichting, C. Maierhofer, M. Kreutzbruck "Crack sizing by laser excited thermography", NDT \& E International, vol.45(1), pp. 133-140, 2012. 